\title{
Renewable Energy Integration in Buildings A Case Study in Portugal
}

\author{
N. Tomás ${ }^{1}$ A. Carvalho ${ }^{2}$ and D. Coelho ${ }^{2,3}$ \\ 1 enernatura \\ Rua Alto das Forcadas, Fracção D, $1^{\circ}$ Esq, 3020-323 Coimbra, Portugal \\ Phone/Fax number:+00351 239001616,e-mail: nuno.tomas@enernatura.pt \\ ${ }^{2}$ ISEC - College of Engineering of Coimbra \\ Rua Pedro Nunes - Quinta da Nora, 3030-199 Coimbra, Portugal \\ Phone/Fax number:+00351239790200, e-mail: dcoelho@isec.pt, anadu@isec.pt \\ ${ }^{3}$ INESC Coimbra, Portugal
}

\begin{abstract}
This paper aims at the presentation of a proposal for the integration of solar thermal technology in buildings, particularised for the Portuguese context through a case study, a new sport public building in Coimbra, which consists of two swimming pools, gym, jacuzzi and sanitary facilities. This proposal has been developed in the framework of a Master dissertation currently under development, which the main objective is the selection of the most appropriate technological solution for the integration of renewable energy in buildings. In this paper we propose the selection of the most appropriate technological solution for the integration of three thermal solar systems in the new building. Two systems are used for heating the swimming pools and the third one is dedicated to domestic hot water. The selection of the best solution will take into account the constructive aspects of the building, the building's energy needs and the local availability of renewable resources and market technologies. For each solar thermal system, the general scheme of the proposed technical solution is presented. Investment costs and economic viability of the selected solutions are also presented.
\end{abstract}

\section{Key words}

Renewable energies, Solar energy, Solar thermal technology, Integration, Buildings,

\section{Introduction}

It is a well-known fact that, in general, cities are regions of high concentration of energy demand (be it in services, residential sector or transports) and, consequently, responsible for a high amount of greenhouse gases (GHG) emissions, including $\mathrm{CO}_{2}$.

Buildings are generally one of the main energy consumers in the urban context. Globally, buildings are responsible for approximately $40 \%$ of the total world annual energy consumption. Most of this energy is for the provision of lighting, heating, cooling, and air conditioning [1]. In Portugal, the building sector has the second highest growth rate of energy consumption, immediately after the transport sector. According to recent data from energy balances of the General Directorate for Energy and Geology [2], residential and services buildings account for about $30 \%$ of final energy and more than $60 \%$ of all electricity consumed at the national level, that reflects in a greater weight in distribution of primary energy by sector and also a greater share of emissions of GHG.

One way of reducing building energy consumption is to design buildings, which are more economical in their energy use. Passive measures, particularly natural or hybrid ventilation rather than air-conditioning, can dramatically reduce primary energy consumption [1]. However, exploitation of renewable energy in buildings offers the opportunity to diminish energy dependence, reduce pollutant emissions and create new employment.

The main objective and challenge of renewable energy integration in buildings is the incorporation of systems technically and economically viable in collecting and processing of renewable energy sources that are useful for building, contributing to the achievement of energy efficient buildings.

In this paper we present a proposal for the integration of three solar thermal systems in a new sport public building in Coimbra. The selection of the best solution for this specific building takes into account the constructive aspects of the building (location, orientation, construction materials), the building's energy needs (lighting, air conditioning, hot water), local resources viability, market availability and technology maturity.

The paper starts by presenting some considerations of the solar thermal integration in buildings. Section 3 presents the case study, with building's description, technical 
solutions for the three solar thermal systems considered, investment costs and economic viability of the selected technologies. The paper ends with some concluding remarks.

\section{Solar thermal integration in buildings}

Renewable energies are growing at a much faster pace than the rest of the economy in Europe and worldwide. This and the dramatic oil price increases in 2005 have led to a remarkable re-evaluation of the renewable energy sector by politics and financing institutions [3].

According to [4] the utilization of solar energy is not a new concept; in ancient Egypt, Mesopotamia and roman cities, architects took account of the relationship between buildings and the surrounding environment. Environmentally oriented buildings are those consciously designed for collecting solar energy. Based on this definition, contemporary buildings should benefit from solar energy in cold seasons regarding the influence of location, orientation, shape, and construction of buildings.

Solar collectors can be integrated into building facades due to the fact that integrating solar systems in the building envelope often is a necessity if the systems are to be economically feasible. Presently, solar collectors have been used in a variety of applications including solar hot-water supplying, solar space heating and cooling. Solar water collectors have undergone a rapid development; they are installed with the main purpose of preheating domestic hot water and/or to cover a fraction of the space heating demand [5].

Solar thermal technologies are not yet playing the important role they deserve in the reduction of buildings' fossil energy consumption and consequent greenhouse gas emissions, even though the increasing oil price has recently started to budge the market. It appears that optimized technologies and competitive prices alone are not sufficient to reach the spread solar thermal technologies could expect.

The results from a detailed survey presented in [6] highlighted how all the system characteristics affecting the building appearance have an impact on integration quality: size and position of collector field; shape and size of the modules; type of jointing; collector material and surface texture and absorber colour.

\section{The case-study of a sport public building in Coimbra}

The sport public building is new and built according with the highest thermal standards. There is a very high emphasis on improving the building's low energy consumption. Taking 14 meters of height, the building is composed of approximately 2150 sq. meters that make up two swimming pools (designed us competition pool and learning pool), gym, jacuzzi and sanitary facilities.
It main characteristics are: south orientation of the main façade, a flat roof with an available area of $1430 \mathrm{sq}$. meters, where solar thermal collectors can be installed and a sloped roof with an area of 334 sq. meters south oriented. Building design is presented in figure 1.

One of the main objectives of this work is to find a technical solution for the integration of three thermal solar systems. Two systems are used for heating swimming pools and the third one is dedicated to domestic hot water (DHW).

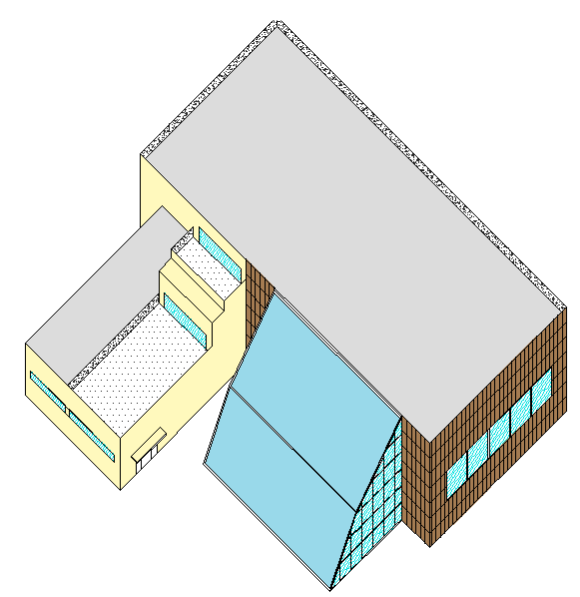

Fig. 1. Building design.

\section{A. Solar heating for competition pool}

The competition pool has an area of $400 \mathrm{~m}^{2}$ and a volume of $880 \mathrm{~m}^{3}$. The pool's operation is the same every day, from 9 AM to 10 PM, except August, when the pool closes for holiday and for equipment maintenance. The number of users of the competition pool is presented in Table I.

Table I. - Number of users of the competition pool.

\begin{tabular}{|c|c|}
\hline TIMETABLE & NUMBER OF USERS \\
\hline $09-10$ & 10 \\
\hline $10-11$ & 10 \\
\hline $11-12$ & 10 \\
\hline $12-13$ & 10 \\
\hline $13-14$ & 10 \\
\hline $14-15$ & 10 \\
\hline $15-16$ & 20 \\
\hline $16-17$ & 20 \\
\hline $17-18$ & 25 \\
\hline $18-19$ & 30 \\
\hline $19-20$ & 20 \\
\hline $20-21$ & 10 \\
\hline $21-22$ & 10 \\
\hline
\end{tabular}

For this pool, from the operating parameters selected: Temperature of water renewal- $15{ }^{\circ} \mathrm{C}$; Pool temperature$26{ }^{\circ} \mathrm{C}$; Replacement of water-4\%, using SolTerm software [7], the following requirements were obtained: Temperature of water injection-37 ${ }^{\circ} \mathrm{C}$; Thermal requirements-1278 $\mathrm{kWh} /$ day. 
The collector SK500L [8] has been chosen, not only by it presence in a national campaign program [9], but also because of the existence of several examples of use of such equipment in large installations in Europe.

According thermal requirements and considering a solar fraction of about $50 \%$, the installation needs a collector array of 80 collectors, having a capture area of 176 sq. meters, and a 14,000 1. storage capacity of hot water.

The collector array is arranged as showed in figure 2, to ensure hydraulic balance. Collectors will be installed on the flat roof with an available area of 1430 sq. meters and with an angle around $65^{\circ}$.

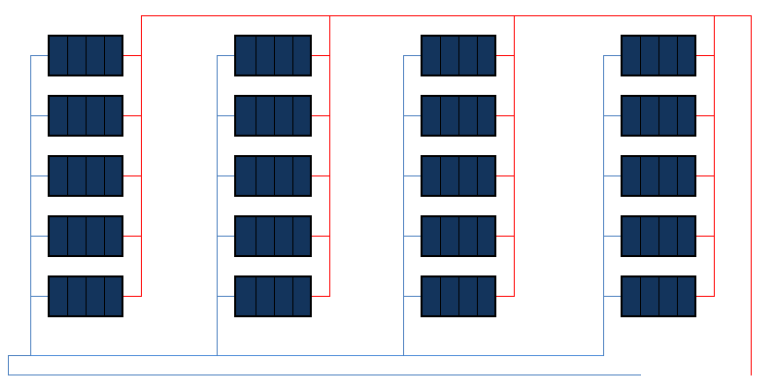

Fig. 2. The collector array

As a backup of the solar energy heat source, an auxiliary heater was mounted. This auxiliary heater is a Buderus Logano Plus SB 315 [10] natural gas boiler with a heating capacity of $70 \mathrm{~kW}$. As the storage capacity is 140001 , for optimizing the system, two storage tanks with a capacity of 70001 each were used.

The general scheme of the heating system for competition pool is presented in figure 3 .

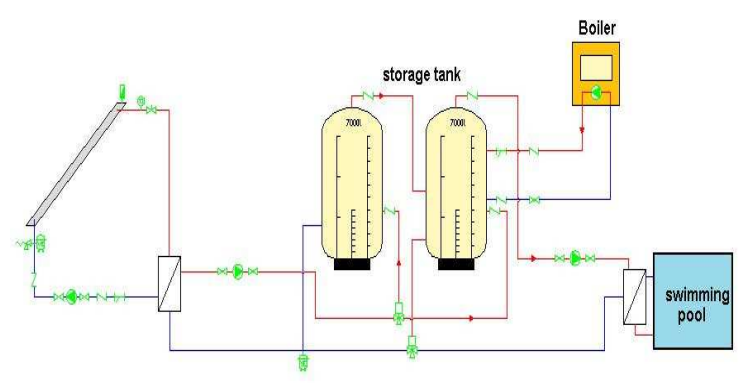

Fig. 3. Scheme of the heating system for .competition pool.

\section{B. Solar heating for learning pool}

The learning pool has an area of $102 \mathrm{~m}^{2}$ and a volume of $125 \mathrm{~m}^{3}$ and the pool's operation is similar to the competition pool. The number of users of the learning pool was considered 10 along all the timetable

From the operating parameters selected for learning pool: Temperature of water renewal- $15{ }^{\circ} \mathrm{C}$; Pool temperature$25{ }^{\circ} \mathrm{C}$; Replacement of water - 3\%, using SolTerm software [7], the following requirements were obtained:
Temperature of water injection-37 ${ }^{\circ} \mathrm{C}$; Thermal requirements-200 kWh/day.

To standardize the installation, the same solar collectors used for competition pool have been chosen for the learning pool thermal system. Since the system of stratification is a very efficient system, a backup of the solar energy heat source is not necessary. The general scheme of the heating system for learning pool is similar to the one presented in figure 3 , excluding the auxiliary heater.

\section{Solar heating for domestic water}

The daily hot water requirements presented in Table II was calculated according to the number of users and assuming a consumption of 40 litters of hot water for user. As for public services, the hot water temperature considered was $45^{\circ} \mathrm{C}$.

Table II. - Hot water requirements.

\begin{tabular}{|c|c|}
\hline TIMETABLE & $\begin{array}{c}\text { HOT WATER } \\
\text { REQUIREMENTS (1) }\end{array}$ \\
\hline $09-10$ & 800 \\
\hline $10-11$ & 800 \\
\hline $11-12$ & 800 \\
\hline $12-13$ & 800 \\
\hline $13-14$ & 800 \\
\hline $14-15$ & 800 \\
\hline $15-16$ & 1.600 \\
\hline $16-17$ & 2.000 \\
\hline $17-18$ & 2.200 \\
\hline $18-19$ & 2.400 \\
\hline $19-20$ & 2.000 \\
\hline $20-21$ & 960 \\
\hline $21-22$ & 800 \\
\hline Total & 16.760 \\
\hline
\end{tabular}

The operating principle of the solar DHW system is identical to the one presented in Figure 4 [8], with an auxiliary heater and a storage tank connected with the DHW production module. For this module, which will perform heat exchange with the storage tank, the DHW Sonnenkraft/FWM35 [8] module production has been chosen.

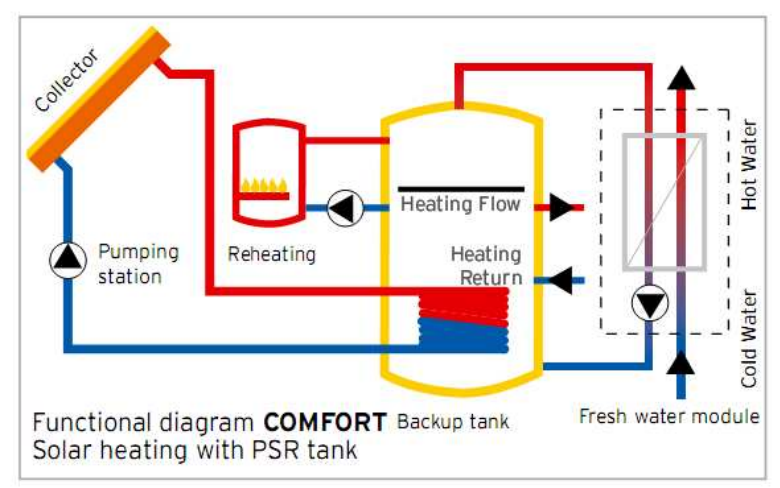

Fig. 4. Operating principle of the solar DHW system. 
Figure 5 presents the general scheme of the heating system for domestic water. The collector SK500L [8] has been also chosen for this system, for the reasons referred above.

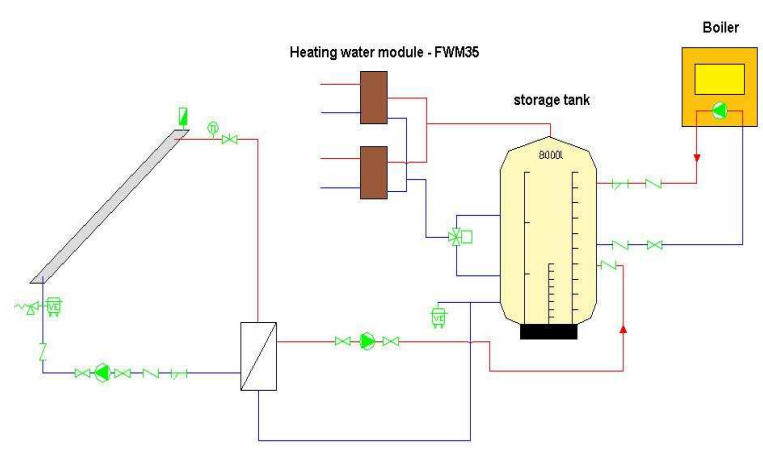

Fig. 5. Scheme of the heating system for domestic water.

Figure 6 depicts the integration of all the solar systems technologies considered for the sport public building: solar thermal systems and photovoltaic systems also projected to the building but not referred in this paper.

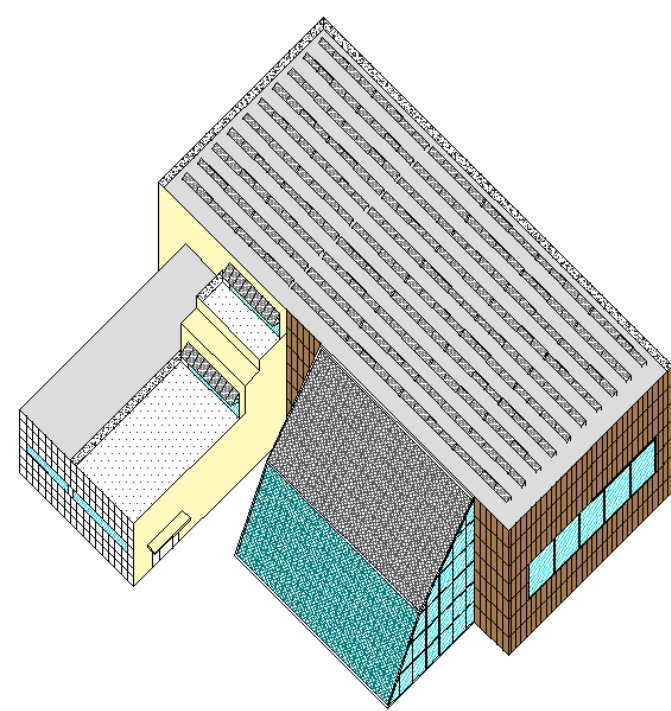

Fig. 6.. Integration of all the solar systems technologies.

\section{Economic Analysis}

Costs associated with the solar thermal system for competition pool, taking into account the selected materials, are presented in Table III. The total investment cost of the installation is $146.964,35 €$. This is also the total investment cost for the solar thermal system for learning pool, since equipment to be used has the same characteristics.

Costs associated with the solar thermal system for domestic hot water, taking into account the selected materials, are presented in Table IV. The total investment cost of the installation is $135576.98 €$.
Table III. - Costs of thermal solar systems for pools.

\begin{tabular}{|c|c|c|}
\hline DESCRIPTION & QUANTITY & $\begin{array}{c}\text { TOTAL } \\
\text { PRICE }(€)\end{array}$ \\
\hline Solar thermal collector & 80 & 70400 \\
\hline End caps & 20 & 42 \\
\hline Gasket & 5 & 183 \\
\hline Fixation system & 20 & 23660 \\
\hline Storage tank (7000 l) & 2 & 15080 \\
\hline Stratified charging module & 1 & 8745 \\
\hline Connection pipe and accessories & 1 & 2500 \\
\hline Antifreeze & 1 & 1068 \\
\hline Flow volume meter & 5 & 865 \\
\hline Three-way motor valve & 2 & 172.6 \\
\hline Expansion tank (400 1) & 1 & 800 \\
\hline Expansion tank (700 1) & 1 & 1800 \\
\hline \multirow[t]{3}{*}{ Circuit control unit } & 1 & 474 \\
\hline & Sub-total & 127789.60 \\
\hline & VAT $12 \%$ & 15334.75 \\
\hline \multirow[t]{3}{*}{ Labor } & & 3200 \\
\hline & VAT $20 \%$ & 640 \\
\hline & Total & 146964.35 \\
\hline
\end{tabular}

Table IV. - Costs of thermal solar system for DHW

\begin{tabular}{|l|l|r|}
\hline DESCRIPTION & QUANTITY & \multicolumn{1}{|c|}{$\begin{array}{c}\text { TOTAL } \\
\text { PRICE }(€)\end{array}$} \\
\hline Solar thermal collector & 80 & 70400 \\
\hline End caps & 20 & 42 \\
\hline Gasket & 5 & 183 \\
\hline Fixation system & 20 & 23660 \\
\hline Storage tank (8000 1) & 1 & 8240 \\
\hline Production hot water module & 2 & 3584 \\
\hline Plate heat exchanger & 1 & 1920 \\
\hline Connection pipe and accessories & 1 & 2500 \\
\hline Antifreeze & 1 & 1068 \\
\hline Flow volume meter & 5 & 865 \\
\hline Three-way motor valve & 1 & 86.3 \\
\hline Expansion tank (400 1) & 1 & 800 \\
\hline Expansion tank (700 1) & 1 & 1800 \\
\hline Circuit control unit & 1 & 474 \\
\hline \multirow{2}{*}{} & Sub-total & $\mathbf{1 1 7} \mathbf{6 2 2 . 3 0}$ \\
\cline { 2 - 3 } & VAT 12\% & $\mathbf{1 4 1 1 4 . 6 8}$ \\
\hline Labor & & 3200 \\
\hline \multirow{2}{*}{} & VAT 20\% & $\mathbf{6 4 0}$ \\
\cline { 2 - 3 } & Total & $\mathbf{1 3 5} \mathbf{5 7 6 . 9 8}$ \\
\cline { 2 - 3 }
\end{tabular}

The economic analyses, presented in Table V, of the three thermal solar systems considered in the study were carried out with SolTerm software [7].

Table V. - Economic analyses of the three thermal solar systems

\begin{tabular}{|l|r|r|r|}
\hline & \multicolumn{1}{|c|}{$\begin{array}{c}\text { COMP. } \\
\text { POOL }\end{array}$} & $\begin{array}{c}\text { LEARN. } \\
\text { POOL }\end{array}$ & DHW \\
\hline Initial costs $(€)$ & -146.964 & -146.964 & -135.577 \\
\hline Avoided energy costs $(€)$ & 530.636 & 309.803 & 518.980 \\
\hline Reinvestments $(€)$ & 185.366 & 100.875 & 182.251 \\
\hline Maintenance $(€)$ & -35.569 & -35.569 & -32.763 \\
\hline Recovery $(€)$ & -1.784 & -1.784 & -1.644 \\
\hline Balance $(€)$ & 535.130 & 534.625 & 534.625 \\
\hline Simple pay-back (years) & 12 years & 20 years & 11 years \\
\hline Net Present Value $(€)$ & 216.608 & 11.373 & 227.589 \\
\hline Internal Rate of Return $(\%)$ & $6,7 \%$ & $2,3 \%$ & $7,1 \%$ \\
\hline
\end{tabular}


As we can see from Table $\mathrm{V}$, all the systems present economical benefits during the 20 years of its life time. This is more evident for the competition pool and DWH systems.

If the national/governmental subsidies available for solar thermal systems in public services were considered in the benefit analysis, the results would be much more attractive.

\section{Conclusion}

The exploitation of renewable energy in cities, namely in buildings, offers the opportunity to diminish energy dependence, reduce pollutant emissions and create new employment

The integration of solar collectors can be accomplished in different ways, depending on the characteristics of the building, on the space for the installation and on the thermal requirements of the system. Collectors can be installed or integrated into a sloping roof, integrated into building facades or mounted with bracket on flat roof or surface.

In this paper we present a proposal for the integration of three thermal solar systems in a new sport public building in a Portuguese city. Two systems are used for heating swimming pools and the third one is dedicated to domestic hot water. The main objective of this work was the selection of the most appropriate technological solution for the integration of renewable energy in this specific building. The selection of the best solution took into account the constructive aspects of the building (location, orientation, construction materials), the buildingl's energy needs and the local availability of renewable resources and market technologies.

It was found that solar thermal technologies can be a sustainable option, economically viable, financially rewarding and environmentally friendly, namely for domestic hot water systems and for applications with high thermal requirements, with a simple pay-back of 11 and 12 years, and with an internal rate of return of $7,1 \%$ and $6,7 \%$, respectively.

\section{References}

[1] A. M. Omer, "Energy, environment and sustainable development", Renewable and Sustainable Energy Reviews, 2008, Vol. 12, pp. 2265-2300.

[2] General Directorate for Energy and Geology, www.dgge.pt.

[3] A. J. Waldau, "Photovoltaics and renewable energies in Europe", 2007, Renewable and Sustainable Energy Reviews, Vol. 11, pp. 1414-1437.

[4] H. H. Alzoubi, A. A. Alshboul, "Low energy architecture and solar rights: Restructuring urban regulations, view from Jordan”, 2010, Renewable Energy, Vol. 35, pp. 333-342.

[5] X.Q. Zhai, R.Z. Wang, Y.J. Dai, J.Y. Wu, Q. Ma, "Experience on integration of solar thermal technologies with green buildings", 2008, Renewable Energy, Vol. 11, pp. 1414-1437.
[6] M. C. M. Probst, C. Roecker, "Towards an improved architectural quality of building integrated solar thermal systems (BIST) ", 2007, Solar Energy, Vol. 81, pp. 1104-1116.

[7] INETI, "SolTerm Software - Performance analysis of thermal and photovoltaic systems (in portuguese)", 2008.

[8] Sonnenkraft, System solutions, 2008, www.sonnenkraft.com.

[9] Solar panels - Solar panels manufacturers, (in portuguese)", 2009, www.paineissolares.gov.pt/inst_marcas.html.

[10] Buderus Catalogue, 2008, www.buderus.pt/files. 